\title{
Current concepts on carotid artery-cavernous sinus fistulas
}

Jordi X. Kellogg, M.D., Todd A. Kuether, M.D., Michael A. Horgan, M.D., Gary M. Nesbit, M.D., and Stanley L. Barnwell, M.D., Ph.D.

Department of Neurosurgery and the Dotter Interventional Institute, Oregon Health Sciences University, Portland, Oregon

With greater understanding of the pathophysiological mechanisms by which carotid artery-cavernous sinus fistulas occur, and with improved endovascular devices, more appropriate and definitive treatments are being performed. The authors define cartoid cavernous fistulas based on an accepted classification system and the signs and symptoms related to these fistulas are described. Angiographic evaluation of the risk the lesion may pose for precipitating stroke or visual loss in the patient is discussed. The literature on treatment alternatives for the different types of fistulas including transvenous, transarterial, and conservative management is reviewed.

Key Words * carotid artery-cavernous sinus fistula * review

Arteriovenous fistulas in the region of the cavernous sinus are commonly classified into two major categories based on the location of the fistula. The first category includes the direct fistula and is termed, by the angiographic classification of Barrow, et al.,[3] a Type A carotid-cavernous sinus fistula (CCF). In Type A fistulas there is a direct connection between the internal carotid artery (ICA) and the cavernous sinus (Fig. 1). These fistulas usually occur posttrauma, although spontaneous causes secondary to other medical conditions have been reported. $[8,35,54]$ The other category of CCF is the indirect type. This lesion is an arteriovenous fistula in the dura around the cavernous sinus. Barrow, et al., described three types of indirect fistulas depending on the dural arterial supply. A CCF that derives its arterial feeding vessels entirely from small branches of the cavernous portion of the ICA is a Type B fistula. The CCF that derives its arterial blood flow from external carotid artery (ECA)-supplied dural vessels is a Type $\mathrm{C}$ fistula. Type D fistulas are CCFs with both ICA and ECA supply.

A direct or Type A CCF is usually the result of a traumatic fracture of the sphenoid bone. This fistula may also result from iatrogenic trauma, including surgery for tumor in the region of the sphenoid sinus, retrogasserian rhizotomy, trigeminal balloon microcompression gangliolysis, or the use of an endovascular device. $[2,35,38,45,59]$ Rupture of an intracavernous ICA aneurysm commonly causes direct fistulas in an older population of patients.[7] This is also seen in patients with connective tissue disorders in whom the intracavernous ICA is weak, such as those with Ehlers-Danlos syndrome and fibromuscular dysplasia.[7,20,36,55] 
The onset of indirect CCF is usually spontaneous. Postmenopausal women in the sixth and seventh decade of life are more commonly affected than men.[21,57] Rarely indirect CCF can be caused by traumatic injury to an intracavernous ICA branch or injury to a dural arterial feeding vessel.[31,51]

\section{SIGNS AND SYMPTOMS}

Patients with both direct and indirect CCFs present similarly, but their symptoms may vary in severity; those with the indirect type often have less severe symptoms because of the lower blood flow. The clinical syndrome relates to the pattern of venous drainage.[1,37,40,52,58] The patients present with headaches (orbital or retroorbital), ophthalmoplegia (usually unilateral but also bilateral), bruit, exophthalmos, chemosis, and decreased vision. Diplopia usually results from dysfunction of the abducent nerve that courses free within the cavernous sinus; the oculomotor and trochlear nerves that course within the cavernous sinus wall may also be affected. Bruits are present in most cases of direct CCFs and in approximately half the number of patients with the indirect type.[32] The bruits may not be audible by auscultation in the indirect type of CCF, but the patient may report its presence, which is often heard at night. The exophthalmos results from venous congestion of the orbit. Redness of the eye vessels results from the arterialization and dilation of the veins in the conjunctiva and sclera. Chemosis results from the increased venous pressures. Loss of vision is a risk secondary to ischemia and, if left untreated, may become irreversible.[17,54] Ischemia to the eye results from a low mean ophthalmic arterial pressure coupled with elevated venous pressures.

\section{NEUROIMAGING EVALUATION}

Performing angiography in patients with a CCF is complex but important in determining the risk the lesion may pose for causing stroke and in selecting the appropriate treatment.[47] In evaluating direct CCFs, determining the site of the defect in the carotid artery can be difficult. The fistula flow may be so high, causing steal phenomena from the intracranial circulation, that it prevents the opacification of the ICA distal to the defect. Obscuration of the ICA by rapid filling of the cavernous sinus veins after the injected contrast material may also occur. Some of these problems can be overcome by rapid image acquisition, allowing for visualization of the ICA within the cavernous sinus prior to obscuration by the veins. Another technique used when visualization of the fistula and parent artery is difficult is to perform vertebral artery angiography. If a steal phenomenon exists, the vertebral artery angiogram can reveal, via the posterior communicating artery, retrograde filling of the ICA distal to the fistula. If filling of the ICA is not demonstrated, fistula visualization can be accomplished by a vertebral artery injection and compression of the ipsilateral common carotid artery. Determination of the site and extent of the lesion can predict whether the patency of the parent artery can be preserved. Preservation of patency is less likely with complete transection of the ICA, whereas a small hole in the ICA can be repaired while preserving patency.

Evaluation of the venous drainage is critical because the venous drainage determines the clinical manifestations encountered and the risk of the lesion causing stroke in the patient. Cortical venous drainage of the fistula is clearly the biggest risk factor for stroke and hemorrhage.[1,14,29,37,40,52,58] Brainstem edema secondary to venous drainage to the posterior fossa from a direct CCF has been described.[56]

Angiography will help determine the most appropriate treatment. The extent of collateral flow, including the anterior and posterior communicating arteries, is crucial prior to the delivery of any embolic agents 
that may lead to ICA occlusion, whether planned or inadvertent. Complete angiographic evaluation can help predict the patient's tolerance to vessel occlusion. It is important to know whether the contralateral carotid artery may be diseased.

Evaluation prior to permanent carotid artery occlusion is complicated, and there is no consensus on its necessity. There are several tests used to determine patient tolerance to permanent occlusion, including temporary balloon occlusion with pressure measurements and quantitative or qualitative cerebral blood flow measurements. $[11,13,43,44]$ These tests have a limited role in the evaluation of direct CCFs. The fistula, and its associated steal phenomena, may act as a test occlusion in itself.

\section{TREATMENT INDICATIONS}

The natural history of CCFs must be considered when deciding their treatment. The reported incidence of spontaneous closure of indirect CCFs varies from 40 to $90 \%$, depending on how long patients are followed and treated conservatively.[47,49] Considering the high rate of spontaneous resolution, it is not unreasonable to follow these patients and treat them conservatively as long as their visual acuity remains stable and their intraocular pressures remain below $25 \mathrm{~mm} \mathrm{Hg.[57,60]}$

In a study by Halbach and colleagues [18] indications for urgent treatment of CCFs were clearly defined. In their review of 155 patients with direct and indirect CCFs, poor clinical outcomes were related to epistaxis and cortical venous drainage. Clinical factors that indicated a worse prognosis included elevated intracranial pressure, progressive proptosis, diminishing visual acuity, and transient ischemic attacks. In patients with only mild local symptoms without factors portending a worse prognosis, conservative management is suggested.

\section{TREATMENT OF DIRECT CAROTID ARTERY-CAVERNOUS SINUS FISTULAS}

\section{Transarterial Approach}

Most direct CCFs can be treated by a percutaneous transarterial route. A transfemoral approach to the ICA with a guide catheter is most commonly performed. Other innovative approaches to these lesions via the vertebral artery have been described.[8] After the guide catheter has been positioned, a microcatheter is navigated through it up to the level of the fistula. Through or on this microcatheter embolic agents, such as platinum coils (Fig. 1), detachable balloons (Fig. 2), or some combination, are delivered through the hole in the cavernous ICA into the cavernous sinus.[6,16,19,33,48,61] Once in the cavernous sinus, the embolic agent is released, closing the fistula with preservation of flow through the ICA. These embolic agents function by achieving varying degrees of mechanical obstruction, thus slowing of blood flow and promoting thrombosis. 

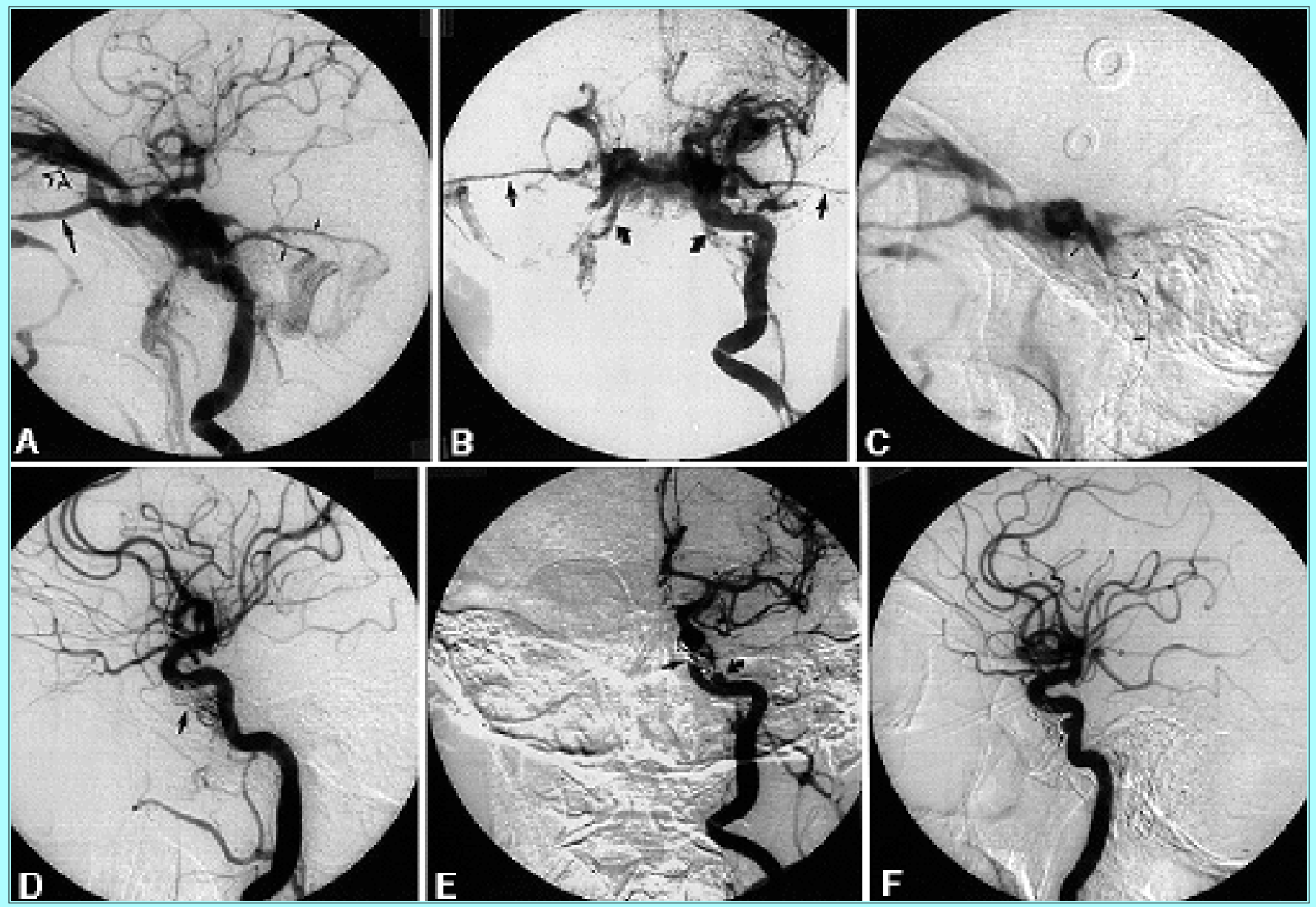

Fig. 1. Angiographic studies obtained in a patient who underwent transarterial embolization to treat a left-sided direct CCF. A: Left ICA angiogram, lateral projection, showing filling of the cavernous sinus with drainage via the SOV (open arrow) and inferior ophthalmic vein (large arrow) and superior petrosal sinus system (small arrows). B: Left ICA angiogram, anteroposterior projection, best shows the drainage by the superior and inferior petrosal sinus bilaterally (large arrows and small arrows, respectively). C: Left ICA, lateral projection, selective angiogram of the fistula through microcatheter (small arrows), revealing drainage via the SOV and inferior ophthalmic vein and inferior petrosal sinus without any significant cortical drainage. Following transarterial embolization of the fistula using two Guglielmi detachable platinum coils, there was no further significant filling of the fistula. D: Left ICA angiogram, lateral projection, revealing fistula closure with coil complex (arrow) in cavernous sinus following embolization. E: Left ICA angiogram, anteroposterior projection, revealing the coil complex (solid arrow) and a small pseudaneurysm (curved arrow), although there is no significant flow through the fistula. F: Left internal carotid angiogram, lateral projection, 4 months after the original embolization procedure revealing a small pseudaneurysm (arrow), with mild coil compaction. The fistula remains closed, and this patient has remained asymptomatic for 3 years. 


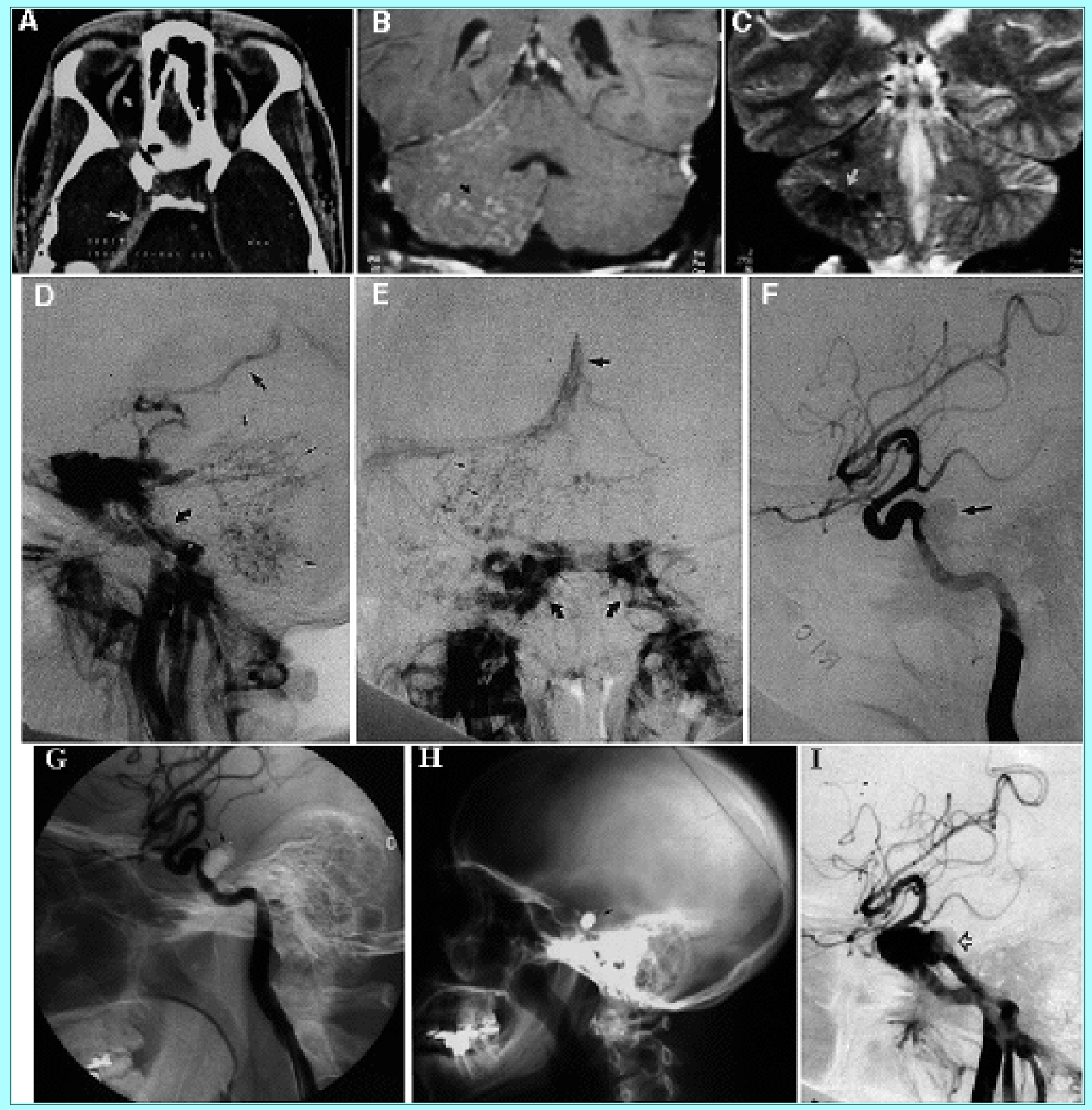

Fig. 2. Imaging studies obtained in a patient in whom a transarterial approach was performed to treat a direct CCF. A: Contrast-enhanced CT of the brain revealing minimal enlargement of the right SOV (curved arrow) and thickening and enhancement of the right petroclinoid ligament (large arrow). B: $\mathrm{T}_{1}$-weighted gadolinium-enhanced magnetic resonance (MR) image of the brain, coronal section, revealing scattered enhancement of the right cerebellar hemisphere (curved arrow). $\mathrm{C}$ : $\mathrm{T}_{2}$-weighted $\mathrm{MR}$ image of the brain, coronal section, revealing areas of decreased signal in the deep sulcal cortex due to hemosiderin staining (arrow). D and E: Right ICA angiogram, lateral projection (D) and anteroposterior projection (E) showing prominent cortical drainage to the cerebellum (small arrows) and the deep venous system (large arrow) and the inferior petrosal sinus bilaterally (curved arrows). A transarterial approach was used with complete occlusion of the fistula with a single detachable balloon. F: Right ICA angiogram, lateral projection, showing the balloon (arrow) 
with no filling of the cavernous sinus. Two days later the patient developed recurrent pulsatile tinnitus. G: A plain radiograph of the head, lateral projection, revealing that the balloon had become partially deflated and shifted posteriorly relative to the sella turcica. $\mathrm{H}$ : Right ICA angiogram, lateral projection, showing the fistula open, although now it does not have cortical drainage to the posterior fossa. After conservative compressive management was tried for 6 weeks because no high-risk venous drainage remained, transarterial embolization was performed using another detachable balloon. I: Right ICA angiogram, lateral projection, showing the fistula has closed. Two balloons can be identified in the cavernous sinus (arrows). The patient tolerated the procedure well and on follow up has had no recurrence of symptoms.

In three large series that reported results in the treatment of direct CCFs by a transarterial route, successful closure of the fistulas while maintaining patency of the ICA was possible in 59 to $88 \%$ of patients. $[6,27,33]$ In most of the patients in whom this was not possible, the fistula was closed by occluding the ICA. Complications are normally not serious and usually require no treatment. A frequent complication includes oculomotor palsies. This is postulated to occur secondary to stretching of the cavernous sinus walls by the embolic agent, particularly if a balloon is used, or by thrombosis after closure of the fistula. These palsies most often resolve spontaneously after a period of weeks to months. In up to $44 \%$ of cases there will be false aneurysms from residual filling of an enlarged cavernous sinus, which frequently will become smaller with time and are usually of no clinical significance.[6] The risk of stroke from an embolic agent is small, with a reported incidence of 2 to $4 \%$.[6,27,33] This low incidence is attributed to the natural flow of aberrant embolic materials or clot into the fistula and veins rather than their migration into the arterial system.

There have been several reports of direct CCFs associated with persistent trigeminal arteries.[6,9,15] The persistent trigeminal artery is the most common carotid-basilar communication, with an incidence of 0.1 to $0.6 \%$ in patients undergoing cerebral angiography. This common abnormality is associated with a variety of cerebrovascular anomalies including aneurysms. Recognition of this anomaly as the source for arterial supply to the fistula may allow for fistula closure with preservation of both the basilar and carotid arteries. $[9,34]$

\section{Transvenous Approach}

When the preferred transarterial approach is not possible or has failed, a femoral transvenous approach to the direct $\mathrm{CCF}$ is performed. Cases in which this may be necessary include proximal occlusion of the ICA caused by noncurative, prior trapping procedures or occlusion secondary to trauma. The access to the cavernous sinus via a transvenous route has been made possible by the development of navigable microcatheter systems. The embolic agents most commonly used are platinum coils delivered through a microcatheter. Septations within the venous channels make introduction of detachable balloon systems difficult. Halbach and colleagues[23] reported on the treatment of 165 direct CCFs in which they used transvenous embolization in 14 of the cases (8\%). In 11 of the 14 patients who underwent a transvenous approach, a cure was achieved, and in one patient there was improvement in symptoms. Complications occurred in two of the patients, one because of perforation of the inferior petrosal sinus and the other because of diversion of blood flow from the cavernous sinus to cortical veins. In one of these cases, a fatal hemorrhage occurred in a patient with Ehlers-Danlos syndrome, with its associated friable blood vessels. 


\section{TREATMENT OF INDIRECT CAROTID ARTERY-CAVERNOUS SINUS FISTULAS}

\section{Transarterial Approach}

The transarterial treatment of indirect CCFs has undergone tremendous evolution.[4,30,39,53] Early reports on the treatment of these lesions began with unselective catheterization of the ECA and embolization with particles or coils. This technique has been abandoned because of a high recurrence rate. Currently, superselective catheterization of small branches supplying the fistula is used when transarterial embolization is performed. Superselective catheterization of the vessels supplying the fistula allows for determination of dangerous collateral vessels between the ECA and the ICA and vertebral artery. Optimum arterial embolization includes occlusion of the vessels as close to the fistula as possible, ideally within the fistula itself. Occlusion of vessels that supply the fistula proximally results inevitably in recurrence of the fistula and often makes its treatment more difficult.

By using superselective catheterization techniques, good results have been reported with transarterial embolization in the treatment of indirect CCFs. In one of the largest series, Halbach and colleagues[21] reported their experiences in treating 22 patients by using transarterial embolization techniques. Complete cure was achieved in $77 \%$ of the patients, and $18 \%$ achieved improvement in their symptoms. Viñuela and coworkers [57] reported on 10 patients with indirect CCFs who were treated with transarterial embolization; nine were completely cured. Debrun, et al.,[6,10] described their results in treating these fistulas, and treatment outcome was related to the type of vascular supply. Type $\mathrm{C}$ fistulas were almost always cured by a transarterial route, whereas Type D fistulas were cured only in $50 \%$ of cases by this route. The difference related to the degree of difficulty in catheterizing the small branches of the cavernous ICA. With the development of new microcatheter systems, even the small branches of the cavernous ICA can be catheterized. Halbach and colleagues[22] reported in 1989 the use of these techniques in difficult type D fistulas. In the four patients with these complicated fistulas, which were supplied by the ECA and small branches of the cavernous ICA, all were cured with transarterial embolization.

Complications related to the transarterial route can include embolization of normal vessels or unrecognized collaterals to the internal carotid or vertebral arteries. Care is taken to avoid these complications by performing lidocaine Wada tests and careful angiographic evaluation before and during embolizations; however, these complications can occur as reported in the previously mentioned large series.[21,57] Angle-closure glaucoma can occur, secondary to acute thrombosis of the superior ophthalmic vein (SOV) after closure of the fistula.[12]

\section{Transvenous Approach}

The preferred method in treating indirect CCFs is via transvenous approach. These lesions are often treated by a combined transarterial and transvenous approach (Fig. 3). Multiple arterial feeding vessels that supply these fistulas make complete transarterial occlusions difficult. The remaining arterial supply tends to enlarge, and the fistula reopens to its original size. 


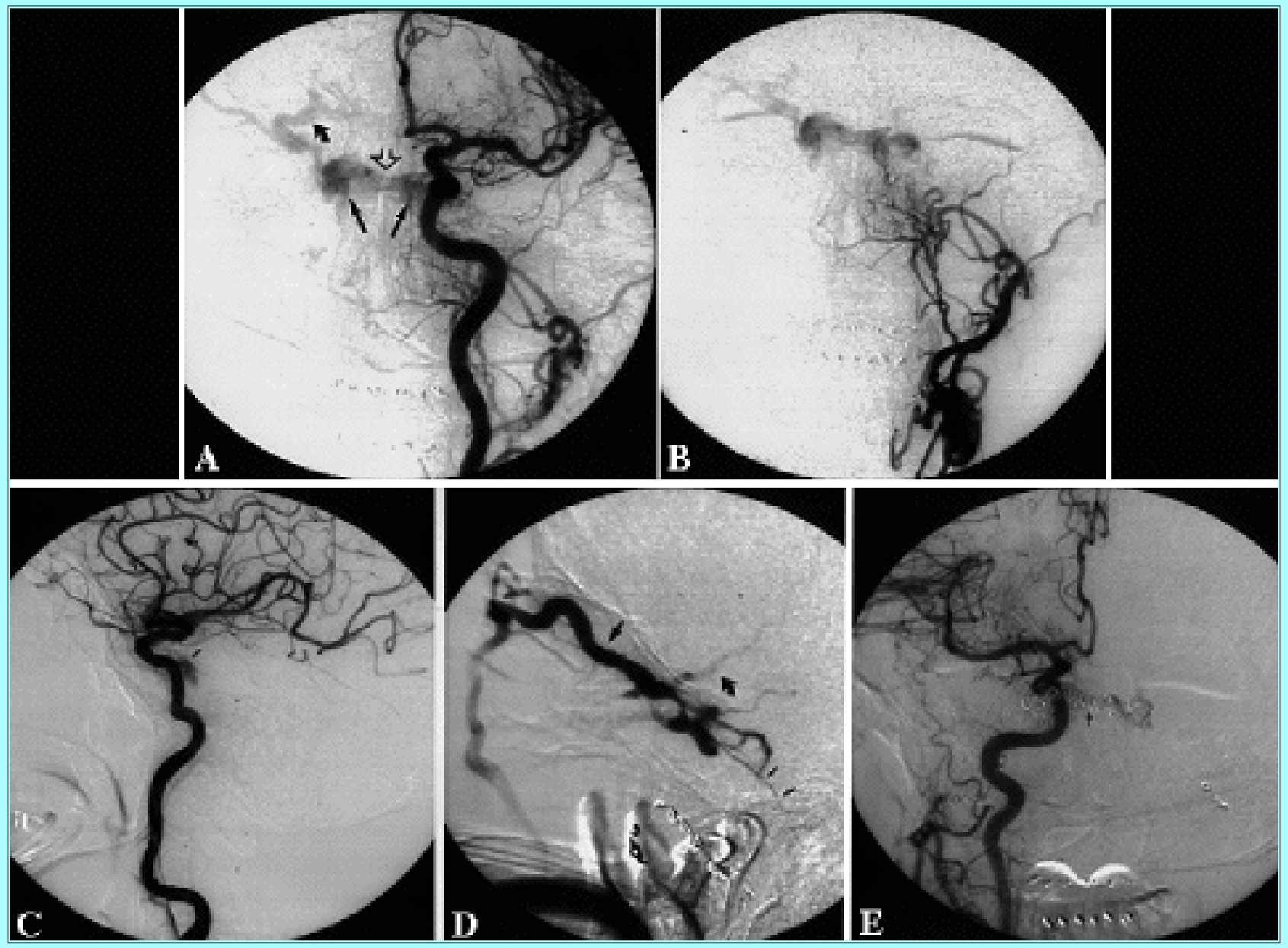

Fig. 3. Angiographic studies obtained in a patient in whom the transvenous approach was performed to treat an indirect CCF. A: Left common carotid artery angiogram, anteroposterior projection, showing filling of the fistula from middle meningeal and ascending pharyngeal branches with a small amount of supply from cavernous carotid branches. The cavernous sinus fills bilaterally (solid arrows) across the intercavernous sinus (open arrow) with SOV (curved arrow) and cortical venous drainage (curved arrow). B: Left ECA angiogram, anteroposterior projection, showing filling of the fistula by branches of the internal maxillary artery. C: Left ICA angiogram showing filling of the cavernous sinus (small arrow) from branches of the meningohypophyseal trunk. The right-sided angiogram revealed similar filling of the fistula by both ICA and ECA branches. The extracranial arterial supply was embolized using polyvinyl alcohol particles and platinum coils following lidocaine challenge test in each branch. A transvenous approach via the right inferior petrosal sinus was then used to catheterize and embolize the right and then left cavernous sinuses as well as the intercavernous sinus. D: Right cavernous sinus angiogram, lateral projection, showing the microcatheter (small arrows) within the inferior petrosal sinus with filling of the SOV (solid arrow) and with drainage into cortical veins along the right sylvian fissure (curved arrow). E: Right ICA angiogram, anteroposterior projection, showing no filling of the fistula following the embolization, the coil complex (arrow) can be seen in the cavernous sinus, bilaterally, and the intercavernous sinus.

In 1974 Mullan[46] proposed transvenous embolization of direct CCFs based both on his and Parkinson's[51] work. In 1987 Courtheoux, et al.,[5] first reported the treatment of the indirect CCFs by the SOV, which is surgically exposed. After exposure, they inserted a catheter directly into the vein to 
deliver coils and the sclerosing agent tetrasulfate. These investigators achieved a complete closure of the fistula. In 1988 Teng, et al.,[56] described five patients with these fistulas successfully treatmented by a direct percutaneous puncture of the SOV and embolization using gelfoam, liquid adhesives, and coils. In 1995, Miller, et al.,[42] described their experience in treating 12 CCFs (two direct, 10 indirect) using a SOV approach. All of these patients had unsuccessful treatments previously or had mechanical reasons necessitating this approach. All 12 patients had complete resolution of their signs and symptoms. Interestingly, detachable balloons were used in 11 of the patients and multiple thrombogenic coils in one patient. There were no intraoperative complications. Following balloon embolization, one patient required embolization of a persistent posterior portion of the fistula via an ipsilateral inferior petrosal sinus approach. One patient developed a complete persistent abducens nerve palsy, eventually requiring strabismus surgery (Fig. 4). Using the SOV as a conduit for embolization can be difficult because of narrowing of the vessel as it passes through the superior orbital fissure.[25] Complications from this approach include rupture of the vein, which causes retroorbital hemorrhage. Authors of a recent report describe a complicated SOV approach that resulted in severe vision loss.[16] Thrombosis of the SOV can also lead to drainage of the fistula through cortical veins and therefore the risk of intracranial hemorrhage.[18,26,41,57] This normally can be avoided by complete closure of the fistula via another route such as the inferior petrosal sinus. Thrombosis of the vein can also lead to angle-closure glaucoma, which may need to be treated by cycloplegic agents, iridectomy, or lateral canthotomy.[12]
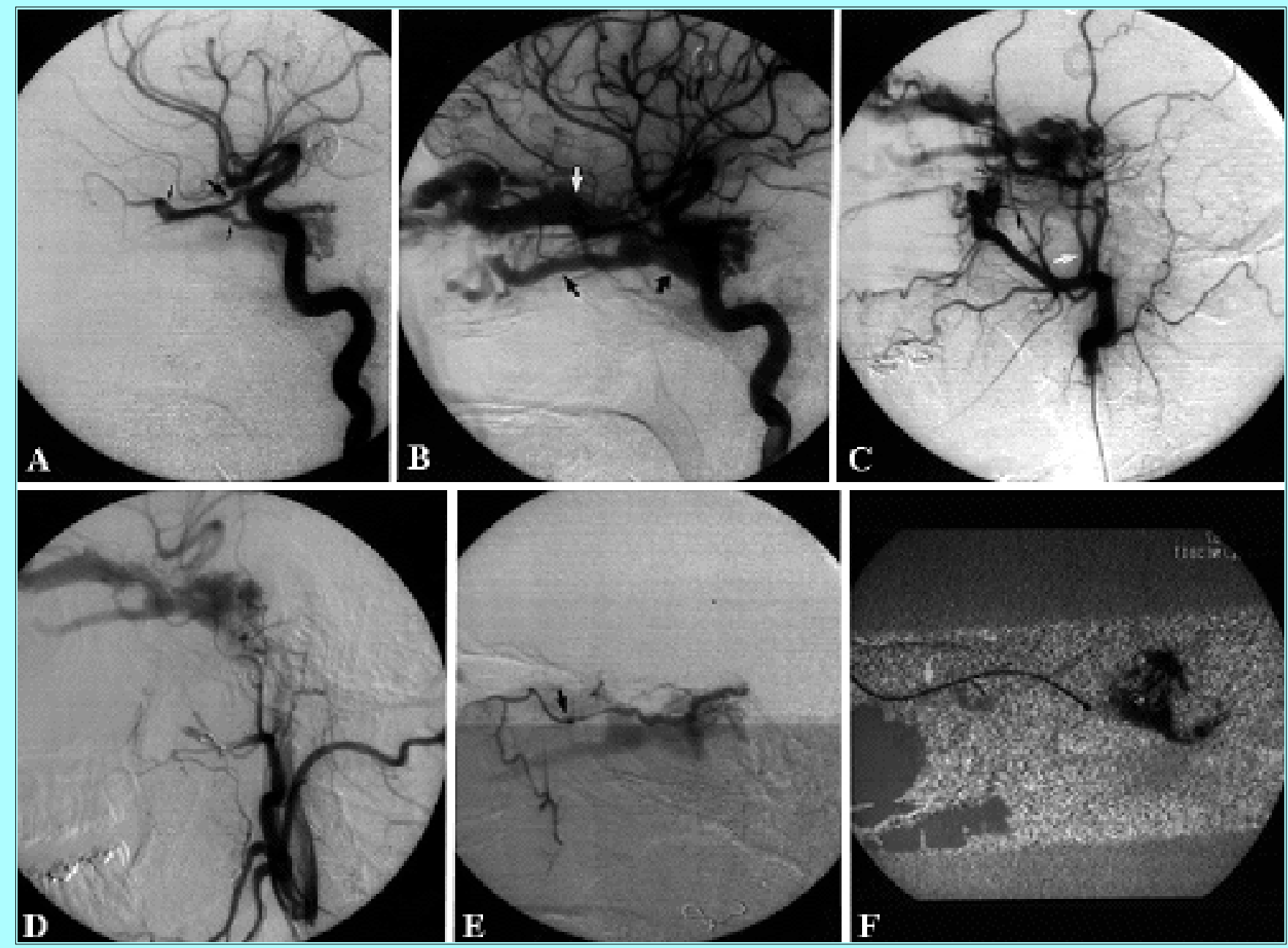

Fig. 4. Angiographic studies obtained in a patient with an indirect CCF. A: Left ICA angiogram (early arterial phase), lateral projection, showing the cavernous sinus filling via a large recurrent branch (small arrows) of the ophthalmic artery (large arrow). B: Left ICA 
angiogram (midarterial phase), lateral projection, showing venous drainage of the cavernous sinus (curved arrow) including the SOV (white arrow) and inferior opthalmic vein (solid arrow) with no petrosal sinus drainage. C: Left ECA angiogram, lateral projection, showing filling of the cavernous sinus from the middle meningeal (white arrow) and internal maxillary artery branches (small arrows). A transvenous catheterization through the ipsilateral inferior petrosal sinus was performed. Selective angiography revealed the posterior compartment to be isolated from the fistulous compartment precluding its use for embolization. Transarterial embolization was performed in the left middle meningeal, left internal maxillary artery, left sphenopalantine, and two branches of the right ascending pharyngeal artery using variable combinations of 50\% glucose, 355 to 500-micron polyvinyl alcohol particles, and platinum coils. D: Left ECA angiogram, lateral projection, revealing marked diminution of flow to fistula following embolization of the internal maxillary artery and middle meningeal artery. The retrograde branch of the ophthalmic artery was then catheterized and embolized to stasis using $50 \%$ glucose and platinum coils. E:

Superselective angiogram of distal ophthalmic artery, lateral projection, prior to embolization showing microcatheter tip at the ophthalmic artery branch point (arrow). Follow-up angiogram revealed complete stasis of flow from the embolized branches with minimal filling of the fistula from bilateral branches of the meningohypophyseal branches. The patient remained neurologically unchanged; the remainder of the fistulous filling was managed conservatively with alternate carotid compression. However, the patient continued to have left eye symptoms and 6 months later underwent repeated angiography, which revealed reconstitution of flow to the fistula. Repeated transarterial embolization of the major feeding vessels was performed. A few days later the patient underwent surgical exposure of the SOV and microcatheter approach to the fistula, which was treated using Guglielmi detachable platinum coils to complete occlusion. F: Intraoperative selective angiogram of the left cavernous sinus, lateral projection, showing the microcatheter (white arrow) as it traverses through the SOV with the tip of the catheter in the cavernous sinus. Note stasis of contrast material within the cavernous sinus indicating closure of the fistula.

Halbach and colleagues[24] reported on the largest series of patients with indirect CCFs treated via a transvenous route. The inferior petrosal sinus is now the preferred route in the treatment of these lesions. The authors treated 13 patients in this manner; 12 patients were cured and one patient improved. This approach is simpler and has fewer risks than via the SOV. There is the risk of rupturing the inferior petrosal sinus or a vessel draining into it, causing a subarachnoid hemorrhage, although this seems to be an infrequent complication.

\section{COMPRESSION THERAPY}

Conservative management of CCFs that do not require urgent treatment can be used before endovascular or surgical options are explored. For indirect CCFs that are draining via the SOV, the patient can apply pressure medially over the eye inferior to the supraorbital ridge intermittently for several minutes. This technique can lead to stasis and closure of the fistula. Higashida, et al.,[28] described a technique of compressing the carotid artery and jugular vein in patients with both direct and indirect CCFs. The group treated using this technique included 71 patients and closure of the fistula occurred in seven of 23 patients with indirect fistulas and eight of 48 patients with direct fistulas. Closure of the fistula occurred within a matter of minutes to 6 months. At 1-year follow up none of the fistulas had reopened. The authors' experiences with this technique have seldom produced any benefit. Whether the compression 
therapy or the natural history of this lesion produces the closure is not known.[49]

\section{CONCLUSIONS}

The patient's signs and symptoms and risk of hemorrhage are related to the venous drainage pattern of the direct or indirect CCF. If drainage is predominantly via the SOV clinical manifestations can include proptosis, chemosis, and arterialization of scleral veins. If the drainage includes cortical venous drainage, the risk for hemorrhage is much higher. If the fistula is not causing progressive loss of vision or does not have cortical drainage, it may be managed conservatively. The endovascular treatment of direct CCFs is usually by transarterial embolization using detachable balloons or platinum coils. If closure of the fistula is not possible via a transarterial route, then transvenous embolization can be performed via the inferior petrosal sinus. For the treatment of indirect CCFs, the transvenous route is, by way of the inferior petrosal sinus or SOV, preferable, using platinum coils as an embolic agent. Transarterial embolization can be used for treatment of these fistulas, although a durable closure requires all of the arterial feeding vessels to be embolized and preferably near or within the fistula.

\section{References}

1. Awad IA, Little JR, Akrawi WP, et al: Intracranial dural arteriovenous malformations: factors predisposing to an aggressive neurological course. J Neurosurg 72:839-850, 1990

2. Barr JD, Mathis JM, Horton JA: Iatrogenic carotid-cavernous fistula occurring after embolization of a cavernous sinus meningioma. AJNR 16:483-485, 19953.

3. Barrow DL, Spector RH, Braun IF, et al: Classification and treatment of spontaneous carotid-cavernous sinus fistulas. J Neurosurg 62:248-256, 1985

4. Black P, Uematsu S, Perovic M, et al: Carotid-cavernous fistula: a controlled embolus technique for occlusion of fistula with preservation of carotid blood flow. Technical note. J Neurosurg 38:113-118, 1973

5. Courtheoux P, Labbe D, Hamel C, et al: Treatment of bilateral spontaneous dural carotid-cavernous fistulas by coils and sclerotherapy. J Neurosurg 66:468-470, 1987

6. Debrun G, Lacour P, Vinuela F, et al: Treatment of 54 traumatic carotid-cavernous fistulas. J Neurosurg 55:678-692, 1981

7. Debrun GM, Aletich VA, Miller NR, et al: Three cases of spontaneous direct carotid cavernous sinus fistulas associated with Ehlers-Danlos syndrome type IV. Surg Neurol 46:247-252, 1996

8. Debrun GM, Ausman JI, Charbel FT, et al: Access to the cavernous sinus through the vertebral artery: technical case report. Neurosurgery 37:144-147, 1995.

9. Debrun GM, Davis KR, Nauta HJ, et al: Treatment of carotid cavernous fistulae or cavernous aneurysms associated with a persistent trigeminal artery: report of three cases. AJNR 9:749-755, 1988

10. Debrun GM, Vinuela F, Fox AJ, et al: Indications for treatment and classification of 132 carotid-cavernous fistulas. Neurosurgery 22:285-289, 1988

11. Erba SM, Horton JA, Latchaw RE, et al: Balloon test occlusion of the internal carotid artery with 
stable xenon/CT cerebral blood flow imaging. AJNR 9:533-538, 1988

12. Golnik KC, Newman SA, Ferguson R: Angle-closure glaucoma consequent to embolization of dural cavernous sinus fistula. AJNR 112:1074-1076, 1991

13. Gonzalez CF, Moret J: Balloon occlusion of the carotid artery prior to surgery for neck tumors. AJNR 11:649-652, 1990

14. Grisoli F, Vincentelli F, Fuchs S, et al: Surgical treatment of tentorial arteriovenous malformations draining into the subarachnoid space. Report of four cases. J Neurosurg 60:1059-1066, 1984

15. Gugliemli G, Vinuela F, Dion J, et al: Persistent primitive trigeminal artery-cavernous sinus fistulas: Report of two cases. Neurosurgery 27:805-809, 1990

16. Guglielmi G, Vinuela F, Duckwiler G, et al: High-flow, small-hole arteriovenous fistulas: treatment with electrodetachable coils. AJNR 16:325-358, 1995

17. Gupta N, Kikkawa DO, Levi L, et al: Severe vision loss and neovascular glaucoma complicating superior ophthalmic vein approach to carotid-cavernous sinus fistula. Am J Ophthalmol 124:853-855, 1997

18. Halbach VV, Hieshima GB, Higashida RT, et al: Carotid cavernous fistulae: Indications for urgent treatment. AJR 149:587-593, 1987

19. Halbach VV, Higashida RT, Barnwell SL, et al: Transarterial platinum coil embolization of carotid-cavernous fistulas. AJNR 12:429-433, 1991

20. Halbach VV, Higashida RT, Dowd CF, et al: Treatment of carotid-cavernous fistulas associated with Ehlers-Danlos syndrome. Neurosurgery 26:1021-1027, 1990

21. Halbach VV, Higashida RT, Hieshima GB, et al: Dural fistulas involving the cavernous sinus: results of treatment in 30 patients. Radiology 163:437-442, 1987

22. Halbach VV, Higashida RT, Hieshima GB, et al: Embolization of branches arising from the cavernous portion of the internal carotid artery. AJNR 10:143-150, 1989

23. Halbach VV, Higashida RT, Hieshima GB, et al: Transvenous embolization of direct carotid cavernous fistulas. AJNR 9:741-747, 1988

24. Halbach VV, Higashida RT, Hieshima GB, et al: Transvenous embolization of dural fistulas involving the cavernous sinus. AJNR 10:377-383, 1989

25. Hanafee W, Rosen LM, Weidner W, et al: Venography of the cavernous sinus, orbital veins, and basal venous plexus. Radiology 84:751-753, 1965

26. Hashimoto M, Yokota A, Matsuoka S, et al: Central retinal vein occlusion after treatment of cavernous dural arteriovenous malformation. AJNR 10 (Suppl):S30-S31, 1989

27. Higashida RT, Halbach VV, Tsai FY, et al: Interventional neurovascular treatment of traumatic carotid and vertebral artery lesions: results in 234 cases. AJR 153:577-582, 1989

28. Higashida RT, Hieshima GB, Halbach VV, et al: Closure of carotid cavernous sinus fistulae by 
external compression of the carotid artery and jugular vein. Acta Radiol Suppl 369:580-583, 1986

29. Hiramatsu K, Utsumi S, Kyoi K, et al: Intracerebral hemorrhage in carotid-cavernous fistula. Neuroradiology 33:67-69, 1991

30. Ishimori S, Hattori M, Shibata Y, et al: Treatment of carotid-cavernous fistula by Gelfoam embolization. J Neurosurg 27:315-319, 1967

31. Jacobson BE, Nesbit GM, Ahuja A, et al: Traumatic indirect carotid-cavernous fistula: report of two cases. Neurosurgery 39:1235-1238, 1996

32. Jørgenson Js, Gutthoff RF: 24 cases of carotid cavernosus fistulas: frequency, symptoms, diagnosis and treatment. Acta Ophthalmol 63 (Suppl 173):67-71, 1985

33. Kendall B: Results of treatment of arteriovenous fistulae with the Debrun technique. AJNR 4:405-408, 1983

34. Kerber W, Manke W: Trigeminal artery to cavernous sinus fistula treated by balloon occlusion. Case report. J Neurosurg 58:611-613,1983

35. Kuether TA, O'Neill OR, Nesbit GM, et al: Direct carotid cavernous fistula after trigeminal balloon microcompression gangliolysis: case report. Neurosurgery 39:853-856, 1996

36. Lach B, Nair SG, Russell NA, et al: Spontaneous carotid-cavernous fistula and multiple arterial dissections in type IV Ehlers-Danlos syndrome. Case report. J Neurosurg 66:462-467, 1987

37. Lasjuanias P, Chiu M, Ter Brugge K, et al: Neurological manifestations of intracranial dural arteriovenous malformations. J Neurosurg 64:724-730, 1986

38. Lister JR, Sypert GW: Traumatic false aneurysm and carotid-cavernous fistula: a complication of sphenoidotomy. Neurosurgery 5:473-475, 1979

39. Mahaley MS Jr, Boone SC: External carotid-cavernous fistula treated by arterial embolization. Case report. J Neurosurg 40:110-114, 1974

40. Malik GM, Pearce JE, Ausman JI, et al: Dural arteriovenous malformations and intracranial hemorrhage. Neurosurgery 15:332-339, 1984

41. Manelfe C, Berenstein A: [Treatment of carotid cavernous fistulas by venous approach. Report of one case.] J Neuroradiol 7:13-19,1980 (Fr)

42. Miller NR, Mosein LH, Debrun GM, et al: Treatment of carotid-cavernous fistulas using a superior ophthalmic vein approach. J Neurosurg 83:838-842, 1995

43. Monsein LH, Jeffery PJ, van Heerden BB, et al: Assessing adequacy of collateral circulation during balloon test occlusion of the internal carotid artery with 99m Tc-HMPAO SPECT. AJNR 12:1045-1051, 1991

44. Moody EB, Dawson RC III, Sandler MP: 99mTc-HMPAO SPECT imaging in interventional neuroradiology: validation of balloon test occlusion. AJNR 12:1043-1044, 1991

45. Motarjeme A, Keifer JW: Carotid-cavernous sinus fistula as a complication of carotid 
endarterectomy. A case report. Radiology 108:83-84, 1973

46. Mullan S: Experiences with surgical thrombosis of intracranial berry aneurysms and carotid cavernous fistulas. J Neurosurg 41:657-670, 1974

47. Newton TH, Hoyt WF: Dural arterial venous shunts in the region of the cavernous sinus. Neuroradiology 1:71-81, 1970

48. Norman D, Newton TH, Edwards MS, et al: Carotid-cavernous fistula: closure with detachable silicone balloons. Radiology 149:149-157, 1983

49. Nukui H, Shibasaki T, Kaneko M, et al: Long-term observations in cases with spontaneous carotid-cavernous fistulas. Surg Neurol 21:543-552, 1984

50. Parkinson D: Carotid cavernous fistula: Direct repair with preservation of the carotid artery. Technical note. J Neurosurg 38:99-106, 1973

51. Parkinson D: A surgical approach to the cavernous portion of the carotid artery. Anatomical studies and case report. J Neurosurg 23:474-483, 1965

52. Pierot L, Chiras J, Meder JF, et al: Dural arteriovenous fistulas of the posterior fossa draining into subarachnoid veins. AJNR 13:315-323, 1992

53. Pugatch RD, Wolpert SM: Transfemoral embolization of an external carotid-cavernous fistula. Case report. J Neurosurg 42:94-97, 1975

54. Sanders MD, Hoyt WF: Hypoxic ocular sequelae of carotid-cavernous fistulae. Study of the causes of visual failure before and after neurosurgical treatment in a series of 25 cases. Br J Ophthalmol 53:82, 1969

55. Schoolman A, Kepes J: Bilateral spontaneous carotid-cavernous fistulae in Ehlers-Danlos syndrome. Case report. J Neurosurg 26:82-97, 1967

56. Teng MM, Guo WY, Huang CI, et al: Occlusion of arteriovenous malformations of the cavernous sinus via the superior ophthalmic vein. AJNR 9:539-546, 1988

57. Viñuela F, Fox AJ, Debrun GM, et al: Spontaneous carotid-cavernous fistulas: clinical, radiological, and therapeutic considerations. Experience with 20 cases. J Neurosurg 60:976-984, 1984

58. Viñuela F, Fox AJ, Pelz DM, et al: Unusual clinical manifestations of dural arteriovenous malformations. J Neurosurg 64:554-558, 1986

59. Wepsic JG, Pruett RC, Tarlov E: Carotid-cavernous fistula due to extradural subtemporal retrogasserian rhizotomy. Case report. J Neurosurg 37:498-500, 1972

60. Wilkins RH: Natural history of intracranial vascular malformations: a review. Neurosurgery 16:421-430, 1985

61. Yang PJ, Halbach VV, Higashida RT, et al: Platinum wire: a new transvascular embolic agent. AJNR 9:547-550, 1988 
Manuscript received August 25, 1998.

Accepted in final form September 3, 1998.

Address reprint requests to: Stanley L. Barnwell, M.D., Ph.D., Department of Neurosurgery (L472), Oregon Health Sciences University, 3181 S.W. Sam Jackson Park Road, Portland, Oregon 97201-3098. email: barnwesl@ohsu.edu. 